\title{
Demographics and Clinical Features of Patients Referred to Headache Specialists
}

\author{
Susan E. Jelinski, Werner J. Becker, Suzanne N. Christie, Rose Giammarco, \\ Gordon F. Mackie, Marek J. Gawel, Arnolda G. Eloff, Jane E. Magnusson
}

\begin{abstract}
Objective: To examine demographic characteristics and clinical features of headache patients referred to neurologists specializing in headache in Canada. Methods: Demographic and clinical data were collected at the time of consultation for 865 new headache patients referred to five headache-specialty clinics in Canada. The Headache Impact Test (HIT-6) and Migraine Disability Questionnaire (MIDAS) were used to measure headache impact and disability. Data were analyzed as part of the Canadian Headache Outpatient Registry and Database (CHORD) Project. Results: The average age of the patients was 40 years and the majority were female $(78 \%)$. Most were employed either full time $(49 \%)$ or part time $(13 \%)$. The majority of patients were diagnosed with either migraine or tension-type headache $(78 \%)$. Over a third of patients experienced headache every day, and half had experienced a headache in the previous month which was of severe intensity. Most (80\%) scored in the "very severe" category of the HIT-6 and over half (55\%) were severely disabled as measured by the MIDAS. Conclusion: Patients referred to headache specialists in Canada are severely disabled by their headache disorders. These patients are in the most productive phase of their lives in terms of age and employment. It is important to provide the best available treatment to headache patients in order to minimize the disability and impact of their headache disorders.
\end{abstract}

RÉSUMÉ: Caractéristiques démographiques et manifestations cliniques chez des patients référés à des spécialistes de la céphalée. Objectif: Examiner les caractéristiques démographiques et les manifestations cliniques de patients souffrant de céphalée qui sont dirigés à un neurologue spécialiste de la céphalée au Canada. Méthodes: Les données démographiques et cliniques ont été recueillies au moment de la consultation chez 865 nouveaux patients dirigés à cinq cliniques spécialisées en céphalée au Canada. Le HIT-6 et le MIDAS ont été utilisés pour mesurer l'impact de la céphalée et de l'invalidité. L'analyse des données a été faite dans le cadre du Canadian Headache Outpatient Registry and Database Project. Résultats: L'âge moyen des patients était de 40 ans et la majorité était des femmes (78\%). La plupart avaient un emploi à temps complet (49\%) ou à temps partiel (13\%). La migraine ou la céphalée de tension était le diagnostic posé chez la majorité des patients (78\%). Plus du tiers des patients souffraient de céphalée quotidienne et la moitié avaient eu un épisode de céphalée sévère dans le mois précédent. La plupart des patients avaient un score les plaçant dans la catégorie «très sévère » au HIT-6 et plus de la moitié (55\%) étaient sévèrement invalidés selon le MIDAS. Conclusion: Les patients qui sont référés à des spécialistes de la céphalée au Canada ont une invalidité importante due à leur maladie. Ils sont dans la période la plus productive de leur vie de par leur âge et leur situation d'emploi. Il est important de fournir aux patients qui souffrent de céphalée le meilleur traitement possible pour minimiser l'invalidité et l'impact de leur céphalée.

Can. J. Neurol. Sci. 2006; 33:228-234

Headache disorders are disabling conditions experienced by many in the general population. Among adult Canadians, the lifetime prevalence of migraine is $7.8 \%$ for males and $24.9 \%$ for females. ${ }^{1}$ Tension-type headache is even more common. An American study found that $38.3 \%$ of the population had experienced an episodic tension-type headache in the past year, and $2.2 \%$ had chronic tension-type headaches. ${ }^{2}$ The socioeconomic cost of headache disorders, particularly migraine, is enormous. For Canadians with moderate to severe intermittent migraine attacks who were participating in a triptan clinical trial, the average annual overall cost due to migraine was estimated to be $\$ 3,025 /$ patient, with most of this $(87 \%)$ due to indirect costs (missed work, etc). ${ }^{3}$ Although many Canadians with headache, even those with migraine, do not consult a physician, ${ }^{4}$ many do turn to the medical profession for help. Fifty percent of American neurologists list headache as one of the foci of their practice, as compared to $46 \%$ for epilepsy and $23 \%$ for chronic pain. ${ }^{5}$ In the United States, headache is also the leading condition for which neurologists indicate that they provide extended or long-term care, with over $77 \%$ indicating they provide such care for

From the Department of Clinical Neurosciences (SEJ, WJB, AGE), University of Calgary, Calgary, AB, Canada; Ottawa General Hospital (SNC,), Ottawa, ON, Canada; McMaster University (RG), Hamilton, ON, Canada; Sunnybrook and Women's College, Health Sciences Centre (MJG), Toronto, ON, Canada; Richmond Hospital (GFM), Richmond, BC, Canada; Department of Psychology (JEM), University of Auckland, Auckland, New Zealand.

Received October 7, 2005. ACCEPTED IN FinAL form DeCEMBer 23, 2005. Reprint requests to: Werner J. Becker, Department of Clinical Neurosciences, Division of Neurology, Foothills Medical Centre, 12th Floor, Neurology, 1403 29th Street NW, Calgary, Alberta, T2N 2T9, Canada. 
patients with headache. ${ }^{5}$ Headache may be somewhat less of a focus for Canadian neurologists, although comparable data are not available. In a 2002 survey done by the Canadian Neurological Society, only $6 \%$ of Canadian neurologists listed pain and/or headache as a specific sub-specialty interest, as compared to $15 \%$ for epilepsy and $14 \%$ for neuromuscular disorders. ${ }^{6}$ Nevertheless, as in other countries, ${ }^{7-10}$ headache is likely the most common reason for patient referral to a neurologist in Canada.

For those headache patients who do choose to seek health care professional advice regarding their headaches, it has been demonstrated in a Norwegian study that consultation with a neurologist generally results in some improvement in headache and self-perceived quality of life. ${ }^{11}$ For migraine, it has been found that after evaluation and treatment by a headache specialist, patients report improved satisfaction with care and significant improvement in headache. ${ }^{12}$ Despite these findings, it appears that many headache sufferers are not satisfied with the medical care they receive, ${ }^{13}$ and many Canadians with headache have either never sought medical care for their headaches, or once they have done so do not return for ongoing care. ${ }^{4}$ This is of concern, given the major disability caused by headache disorders.

The study reported here used a prospective cohort study design to characterize the demographics, diagnosis and selected clinical features of patients with headache referred to five neurological practices in Canada with a special interest in headache disorders. In addition, the degree of disability was quantified using standard measures. Our results show that these patients, for the most part, are at the severe end of the headache spectrum and are indeed a formidable challenge for the Canadian healthcare system.

\section{Patients and Methods}

\section{Subjects}

Data were prospectively collected as part of the Canadian Headache Outpatient Registry and Database (CHORD) project for new patients referred to one of five neurologist outpatient practices in Canada. All neurologists involved were known in their geographic area to have a special interest in the diagnosis and management of headache. The five clinics involved in this study were in Calgary, Hamilton, Ottawa, Toronto, and the greater Vancouver area (Richmond). With the exception of the Calgary centre where patients saw one of two neurologists, all practices were staffed by a single neurologist. Ethical approval for the study was obtained at each centre. All neurologists involved worked as consultants, seeing patients upon referral. The great majority of the patients seen were referred by family physicians. In Canada, there are no specific criteria for referral of a patient with headache to a specialist, and the decision to refer is a clinical decision made by the referring physician in conjunction with the patient.

To avoid selection bias, consecutive new patients seen by the consultant were entered into the database. In some centres, data collection was interrupted for periods of time for logistical and resource reasons. At one centre (which entered 38 patients), because of limited resources and high patient volumes, patients were entered in a semi-random manner as time permitted. Some degree of selection bias in this small patient contribution cannot be ruled out. Overall, data collection occurred over a period of just over two years from September 2001 to January 2004. The exact period of data collection varied somewhat from centre to centre, as additional centres were added over time.

\section{Data Collection}

Pre-specified data including basic demographic information, diagnosis, and other clinical characteristics were collected by the neurologist with the aid of a paper form, and the data were later entered into the database. Demographic information collected included age, gender, highest education level, employment status, marital status, and specialty of referring physician. Diagnoses were made according to International Headache Society (IHS) criteria of $1988,{ }^{14}$ with the exception that patients with chronic daily headache (headache on 15 days a month or more) were diagnosed according to Silberstein et al. ${ }^{15,16}$ If patients received more than one headache diagnosis, the one considered most responsible for the referral was listed first, and this was the diagnosis used in data analysis. A determination as to whether or not symptomatic medication overuse was present was also made by the neurologist according to the criteria of Silberstein et al, ${ }^{15}$ and the type of medication overused was noted. Patients were asked to estimate the number of headache days they had per month at the time of the consultation. This was done with the assistance of headache diaries if these were available. Additionally patients were asked to rate the intensity of the most severe headache that they had experienced in the past month (none, mild, moderate, or severe). "None" was selected if patients experienced no headaches in the month prior to consultation with the headache neurologist. At the time of the consultation, patients also completed two measures of headache related disability, namely the Headache Impact Test (HIT- 6) ${ }^{17}$ and the Migraine Disability Questionnaire (MIDAS) (18-20).

\section{Data Analysis}

All information collected was entered into the CHORD computer database which was specifically designed to collect data from patients with headache disorders. All data were

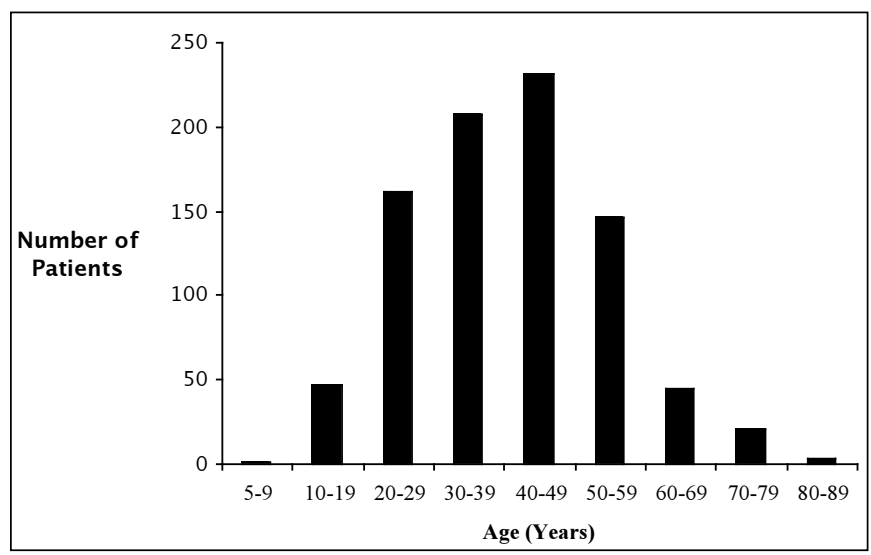

Figure 1: Age distribution of patients. 
stripped of specific patient identifiers before they left each of the five headache clinics, and analyzed centrally. Descriptive statistical analyses were performed using SAS for Windows (release 8.02; SAS Institute Inc., Cary, NC, 1999-2001).

\section{RESUlTS}

Data were collected on 865 patients seen in the five headache centres. The number of patients (and data collection periods) for each of the five centres were as follows: Centre \#1: 357 patients (Nov 2001 - Feb 2003); Centre \#2: 276 patients (Dec 2002 - Jan 2004); Centre \#3: 119 patients (Sept 2001 - Oct 2003); Centre \#4: 75 patients (May 2003 - Dec 2003); Centre \#5: 38 patients (June 2002 - Jan 2004).

\section{Demographic Features}

Demographic features of the patient population are shown in Table 1 . The mean age was 40.3 years $(S D \pm 13.7)$. As shown in

Table 1: Demographic features of patients seen by headache neurologists in Canada. $(\mathbf{n}=\mathbf{8 6 5})$

\begin{tabular}{|c|c|}
\hline Age $($ mean \pm SD) & $40.3 \pm 13.7$ \\
\hline \multicolumn{2}{|l|}{ Gender } \\
\hline Male & $193(22.3 \%)$ \\
\hline Female & $672(77.7 \%)$ \\
\hline \multicolumn{2}{|l|}{ Race } \\
\hline White & $735(93.8 \%)$ \\
\hline \multicolumn{2}{|l|}{ Education* } \\
\hline Elementary-Secondary Only & $340(46.3 \%)$ \\
\hline Less than High School Diploma & $77(10.5 \%)$ \\
\hline High School Diploma or Equivalent & $263(35.8 \%)$ \\
\hline Trades Certificate/Diploma & $56(7.6 \%)$ \\
\hline Community College & $142(19.3 \%)$ \\
\hline University & $196(26.7 \%)$ \\
\hline Some University & $23(3.1 \%)$ \\
\hline University Certificate Below Bachelor's Degree & $9(1.2 \%)$ \\
\hline Bachelor's Degree & $122(16.6 \%)$ \\
\hline University Certificate Above Bachelor's Degree & $6(0.8 \%)$ \\
\hline Medicine, Dentistry, Veterinary Medicine, Optometry & $2(0.3 \%)$ \\
\hline Master's Degree & $30(4.1 \%)$ \\
\hline Doctorate Degree & $4(0.5 \%)$ \\
\hline \multicolumn{2}{|l|}{ Employment Status** } \\
\hline Full Time Outside of Home & $391(49.3 \%)$ \\
\hline Part Time Outside of Home & $100(12.6 \%)$ \\
\hline Full Time Homemaker & $90(11.3 \%)$ \\
\hline Unemployed & $74(9.3 \%)$ \\
\hline Retired From Work Outside of Home & $46(5.8 \%)$ \\
\hline Disability Due to Headache & $43(5.4 \%)$ \\
\hline Disability For Reasons Other Than Headache & $39(4.9 \%)$ \\
\hline Welfare/Social Assistance & $10(1.3 \%)$ \\
\hline \multicolumn{2}{|l|}{ Marital Status $* * *$} \\
\hline Married/Common Law & $471(56.2 \%)$ \\
\hline Single & $261(31.1 \%)$ \\
\hline Divorced/Separated & $90(10.7 \%)$ \\
\hline Widowed & $16(1.9 \%)$ \\
\hline \multicolumn{2}{|l|}{ Referral } \\
\hline Family Physician/GP & $729(84.3 \%)$ \\
\hline Neurologists & $46(5.3 \%)$ \\
\hline
\end{tabular}

*Education status was unknown in 131 patients; \% totals are out of 734

**Employment status was unknown in 72 patients; \% totals are out of 793

*** Marital Status was unknown in 27 patients; \% totals are out of 838
Figure 1, most patients were between the ages of 20 and 60 , while the 40-49 age group was the most populated in our sample. The majority of the patients were female $(n=672 ; 77.7 \%)$, and approximately half of the patients who were referred were married or living common law $(n=471 ; 56.2 \%)$.

Almost $90 \%$ of our patients had at least a high school diploma, and $22 \%(n=164)$ were educated to a Bachelor degree level or higher. More than half of the patients were employed outside of the home $(n=491 ; 61.9 \%)$, either full time $(n=391$; $49.3 \%)$, or part time $(n=100 ; 12.6 \%)$. A further $11.3 \% \quad(n=90)$ identified themselves as full time home makers. Only $5.4 \%$ $(n=43)$ of the patients were receiving disability benefits because of their headache disorder, but an additional $4.9 \%(n=39)$ were receiving a disability pension for other reasons. Only $9.3 \%(\mathrm{n}=$ 74) gave their work status as unemployed.

The vast majority of patients seen $(n=729 ; 84.3 \%)$ were referred to the headache specialist by a family physician, although $5.3 \% \quad(n=46)$ were referred by other neurologists.

\section{Diagnosis}

Patient diagnoses are shown in Table 2. The majority of patients referred to the headache specialists in our study were given a migraine diagnosis $(n=606$; $70.4 \%$ ). Of these, approximately a third $(\mathrm{n}=216 ; 25.1 \%$ of the total patient population) were given a diagnosis of transformed migraine. Approximately half of the patients with transformed migraine $(n=104 ; 48.1 \%)$ had medication overuse.

In only $7.9 \%$ of patients $(n=68)$ was tension-type headache considered the diagnosis most responsible for the patient's referral. The majority of these patients $(\mathrm{n}=$ $46 ; 67.6 \%$ ) were specifically sub-classified as suffering from chronic tension-type headache. Only eight $(n=8 ; 17.4 \%)$ of these chronic tension-type headache patients were considered to have medication overuse and 24 patients $(52.2 \%)$ were specified not to have medication overuse. In the remaining patients, their status with regard to medication overuse was not specifically coded and is therefore not known.

The diagnosis of new daily persistent headache was given to $5.1 \%(n=44)$ of patients. These diagnoses were made before the 2004 IHS diagnostic criteria ${ }^{21}$ were available, and reflected primarily the mode of onset of these continuous headaches. ${ }^{15}$ Twenty-five percent of these patients $(n=11 ; 25 \%)$ were specified to have medication overuse.

With regard to the rarer primary headache syndromes, three patients were given a diagnosis of hemicrania continua, 


\section{Table 2: Diagnoses of patients seen by headache neurologists in Canada $(\mathbf{n}=\mathbf{8 6 0})$ *}

\begin{tabular}{|c|c|}
\hline Diagnosis & No. $(\%)$ \\
\hline Migraine & $390(45.3 \%)$ \\
\hline$M O^{* *}$ & $21(5.4 \%)$ \\
\hline Transformed Migraine & $216(25.1 \%)$ \\
\hline MO & $104(48.1 \%)$ \\
\hline Tension-Type & $68(7.9 \%)$ \\
\hline MO & $10(14.7 \%)$ \\
\hline $\mathrm{NDPH}^{* * *}$ & $44(5.1 \%)$ \\
\hline$M O$ & $11(25.0 \%)$ \\
\hline Headache Associated With Head Trauma & $31(3.6 \%)$ \\
\hline$M O$ & $10(32.3 \%)$ \\
\hline $\begin{array}{l}\text { Headache Associated With Cervical Spine Disorder } \\
\qquad M O\end{array}$ & $7(23.3 \%) \quad 30(3.5 \%)$ \\
\hline Cluster & $23(2.7 \%)$ \\
\hline$M O$ & $2(8.7 \%)$ \\
\hline Other & $58(6.7 \%)$ \\
\hline$M O$ & $12(20.7 \%)$ \\
\hline
\end{tabular}

*No diagnoses was listed for 5 patients; \% totals are out of 860

** $\mathrm{MO}=$ Medication Overuse

***New Daily Persistent Headache

there were five cases of idiopathic stabbing headache, and three cases of chronic paroxysmal hemicrania.

If medication overuse was excluded, the most common secondary headache types seen were headache associated with head trauma $(\mathrm{n}=31 ; 3.6 \%)$, and headaches associated with disorders of the neck (cervical spine) $(n=30 ; 3.5 \%)$. Sinusrelated headache as the most important diagnosis leading to referral was rare and diagnosed in only two patients. A diagnosis of low spinal fluid pressure headache was also given to only two patients.

\section{Clinical Features}

Over a third of patients $(n=310,36.4 \%)$ had headache every day. Just over half of all patients, $55.1 \%(\mathrm{n}=471)$ had headache on 15 days per month or more. As shown in Figure 2a, the

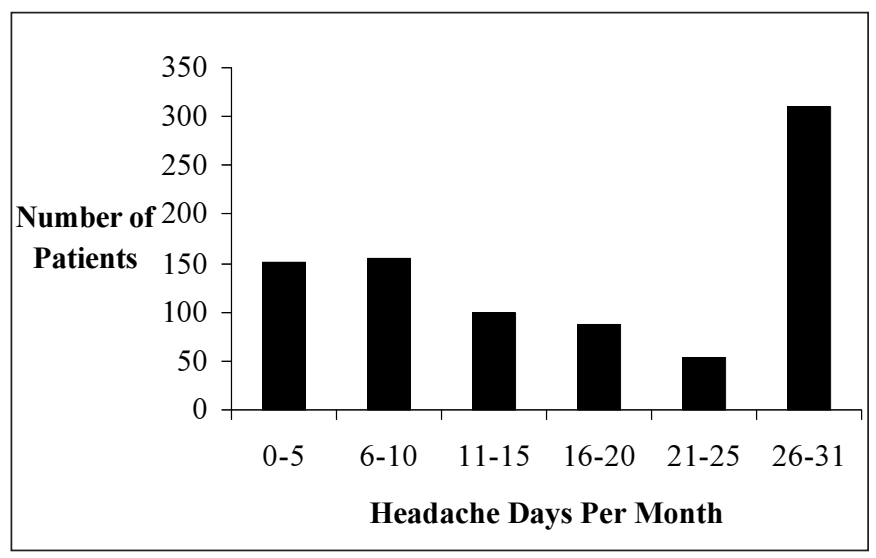

Figure 2a: Number of headache days per month $(n=855)$ majority of the patients who had headaches on more than 15 days a month had headache essentially every day.

As shown in Figure $2 b, 51.4 \%(n=372)$ of patients had experienced at least one headache of severe intensity in the previous month, and a further $37.7 \%(\mathrm{n}=273)$ had experienced a headache of at least moderate intensity. Only $10.8 \%(\mathrm{n}=78)$ had experienced only mild headaches or no headaches in the month prior to the consultation.

\section{Disability}

Table 3 demonstrates the level of disability experienced by our sample of headache patients, shown by diagnostic categories. Headache patients experienced substantial impact and disability as a result of their headaches as indicated by HIT6 and MIDAS scores (Table 3). The majority of patients across all diagnostic categories scored in the "Very Severe" range with the HIT-6. Similarly, over half of all patients in each diagnostic category were severely disabled by their headaches as indicated by MIDAS scores (Table 3). According to the HIT-6, the diagnostic categories in which patients were most impacted by their headaches were transformed migraine, headache associated with head trauma, and headache due to cervical spine disorder. Similarly, these same three diagnostic categories showed the highest mean disability scores on the MIDAS.

\section{Discussion}

Consistent with the epidemiology of headache, the majority of patients referred to the headache specialists in our study were female. According to a Canadian population based epidemiological study, ${ }^{1}$ migraine is just over three times as common in females as in males, and migraine was the dominant diagnosis in our referred patient population. The female to male ratio in our overall referred population was 3.48 to 1 , accurately reflecting the prevalence according to gender in the general population. Our population of patients was also similar to other clinic-based studies of headache in terms of age and various demographic features. ${ }^{22-25}$

Given the episodic nature of headache and the lack of mortality associated with this disorder, headache typically has

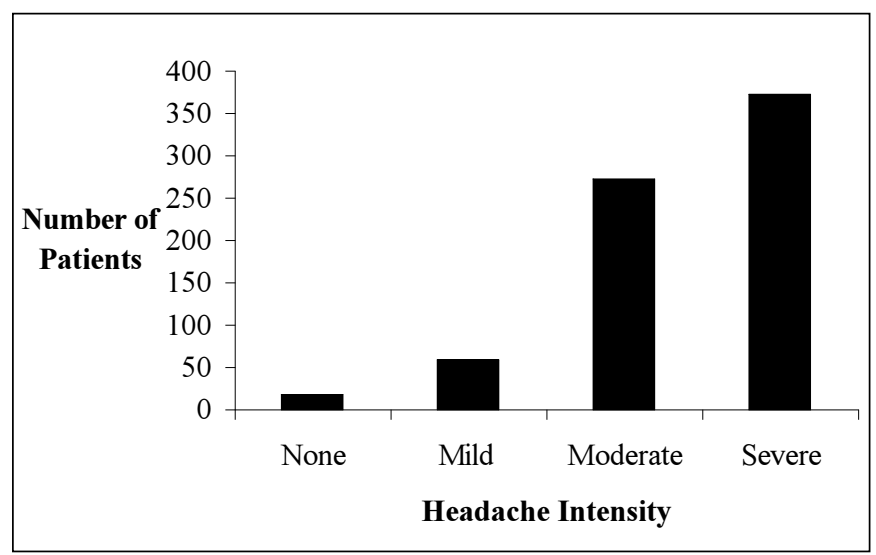

Figure 2b: Headache intensity in previous month $(n=723)$ 
Table 3: Disability in patients seen by headache specialists in Canada, separated by diagnostic categories

\begin{tabular}{|c|c|c|c|c|c|c|c|c|}
\hline & Migraine & $\begin{array}{l}\text { Transformed } \\
\text { Migraine }\end{array}$ & Tension Type & NDPH & Trauma & $\begin{array}{l}\text { Cervical } \\
\text { Spine }\end{array}$ & Cluster & Other \\
\hline HIT-6 & $\mathrm{n}=371$ & $\mathrm{n}=213$ & $n=64$ & $n=44$ & $\mathrm{n}=29$ & $\mathrm{n}=29$ & $\mathrm{n}=22$ & $\mathrm{n}=57$ \\
\hline Score * & $\begin{array}{r}63.1 \\
(62.4-63.7)\end{array}$ & $\begin{array}{r}64.8 \\
(64.2-65.4)\end{array}$ & $\begin{array}{r}63.4 \\
(61.8-65.0)\end{array}$ & $\begin{array}{r}63.3 \\
(61.3-65.2)\end{array}$ & $\begin{array}{r}66.1 \\
(63.4-68.9)\end{array}$ & $\begin{array}{r}64.7 \\
(61.8-67.6)\end{array}$ & $\begin{array}{r}64.1 \\
(61.2-67.1)\end{array}$ & $\begin{array}{r}59.2 \\
(56.6-61.8)\end{array}$ \\
\hline None/Little & $\begin{array}{r}11 \\
(3.0 \%)\end{array}$ & $\begin{array}{r}1 \\
(0.5 \%)\end{array}$ & $\begin{array}{r}3 \\
(4.6 \%)\end{array}$ & $\begin{array}{r}2 \\
(4.6 \%)\end{array}$ & --- & $\begin{array}{r}2 \\
(6.9 \%)\end{array}$ & $\begin{array}{r}1 \\
(4.6 \%)\end{array}$ & $\begin{array}{r}11 \\
(19.3 \%)\end{array}$ \\
\hline Some & $\begin{array}{r}31 \\
(8.4 \%)\end{array}$ & $\begin{array}{r}6 \\
(2.8 \%)\end{array}$ & $\begin{array}{r}2 \\
(3.0 \%)\end{array}$ & $\begin{array}{r}2 \\
(4.6 \%)\end{array}$ & $\begin{array}{r}3 \\
(10.3 \%)\end{array}$ & $\begin{array}{r}1 \\
(3.5 \%)\end{array}$ & -- & $\begin{array}{r}5 \\
(8.8 \%)\end{array}$ \\
\hline Substantial & $\begin{array}{r}45 \\
(12.1 \%)\end{array}$ & $\begin{array}{r}13 \\
(6.1 \%)\end{array}$ & $\begin{array}{r}9 \\
(13.6 \%)\end{array}$ & $\begin{array}{r}6 \\
(13.6 \%)\end{array}$ & $\begin{array}{r}2 \\
(6.9 \%)\end{array}$ & $\begin{array}{l}--- \\
---\end{array}$ & $\begin{array}{r}4 \\
(18.2 \%)\end{array}$ & $\begin{array}{r}8 \\
(14.0 \%)\end{array}$ \\
\hline Very Severe & $\begin{array}{r}284 \\
(76.6 \%) \\
\end{array}$ & $\begin{array}{r}193 \\
(90.6 \%) \\
\end{array}$ & $\begin{array}{r}52 \\
(78.8 \%) \\
\end{array}$ & $\begin{array}{r}34 \\
(77.3 \%) \\
\end{array}$ & $\begin{array}{r}24 \\
(82.8 \%) \\
\end{array}$ & $\begin{array}{r}26 \\
(89.7 \%) \\
\end{array}$ & $\begin{array}{r}17 \\
(77.3 \%) \\
\end{array}$ & $\begin{array}{r}33 \\
(57.9 \%) \\
\end{array}$ \\
\hline MIDAS & $\mathrm{n}=373$ & $\mathrm{n}=208$ & $\mathrm{n}=64$ & $\mathrm{n}=44$ & $\mathrm{n}=31$ & $\mathrm{n}=29$ & $\mathrm{n}=68$ & $\mathrm{n}=56$ \\
\hline Score * & $\begin{array}{r}30.5 \\
(27.1-34.0)\end{array}$ & $\begin{array}{r}67.3 \\
(57.1-77.5)\end{array}$ & $\begin{array}{r}42.1 \\
(28.5-55.7)\end{array}$ & $\begin{array}{r}53.8 \\
(27.3-80.3)\end{array}$ & $\begin{array}{r}107.5 \\
(60.4-154.7)\end{array}$ & $\begin{array}{r}62.7 \\
(35.5-89.9)\end{array}$ & $\begin{array}{r}57.0 \\
(17.9-96.0)\end{array}$ & $\begin{array}{r}31.7 \\
(19.0-44.4)\end{array}$ \\
\hline None/Little & $\begin{array}{r}61 \\
(16.4 \%)\end{array}$ & $\begin{array}{r}20 \\
(9.6 \%)\end{array}$ & $\begin{array}{r}16 \\
(25.0 \%)\end{array}$ & $\begin{array}{r}10 \\
(22.7 \%)\end{array}$ & $\begin{array}{r}3 \\
(9.7 \%)\end{array}$ & $\begin{array}{r}7 \\
(24.1 \%)\end{array}$ & $\begin{array}{r}6 \\
(26.1 \%)\end{array}$ & $\begin{array}{r}26 \\
(46.4 \%)\end{array}$ \\
\hline Mild & $\begin{array}{r}41 \\
(11.0 \%)\end{array}$ & $\begin{array}{r}7 \\
(3.4 \%)\end{array}$ & $\begin{array}{r}4 \\
(6.3 \%)\end{array}$ & $\begin{array}{r}5 \\
(11.4 \%)\end{array}$ & $\begin{array}{r}2 \\
(6.5 \%)\end{array}$ & $\begin{array}{r}1 \\
(3.5 \%)\end{array}$ & $\begin{array}{r}1 \\
(4.4 \%)\end{array}$ & $\begin{array}{r}3 \\
(5.4 \%)\end{array}$ \\
\hline Moderate & $\begin{array}{r}81 \\
(21.7 \%)\end{array}$ & $\begin{array}{r}21 \\
(10.1 \%)\end{array}$ & $\begin{array}{r}8 \\
(12.5 \%)\end{array}$ & $\begin{array}{r}7 \\
(15.9 \%)\end{array}$ & $\begin{array}{r}5 \\
(16.1 \%)\end{array}$ & $\begin{array}{r}3 \\
(10.3 \%)\end{array}$ & $\begin{array}{r}3 \\
(13.0 \%)\end{array}$ & $\begin{array}{r}7 \\
(12.5 \%)\end{array}$ \\
\hline Severe & $\begin{array}{r}190 \\
(50.9 \%)\end{array}$ & $\begin{array}{r}160 \\
(76.9 \%)\end{array}$ & $\begin{array}{r}36 \\
(56.3 \%)\end{array}$ & $\begin{array}{r}22 \\
(50.0 \%)\end{array}$ & $\begin{array}{r}21 \\
(67.7 \%)\end{array}$ & $\begin{array}{r}18 \\
(62.1 \%)\end{array}$ & $\begin{array}{r}13 \\
(56.5 \%)\end{array}$ & $\begin{array}{r}20 \\
(35.7 \%)\end{array}$ \\
\hline
\end{tabular}

*Mean score $(95 \%$ confidence interval)

not been on the forefront of public health initiatives. Nonetheless several lines of research have demonstrated that headache gives rise to significant disability, substantially impacting both work and family life of headache sufferers. Gerth et $\mathrm{al}^{26}$ reported that migraineurs in North America are absent from work approximately 17 days each year. In this same study, migraine sufferers indicated that, in the four weeks prior to being surveyed, they had worked approximately 13 hours with migraine and were only $46 \%$ effective while at work with migraine symptoms. ${ }^{26}$ Von Korff et $\mathrm{al}^{27}$ reported headacheinduced decreased work effectiveness, while working with headache, in the order of $41 \%$ for migraine and $24 \%$ for other headache types. In an American study, $\mathrm{Hu}$ et $\mathrm{al}^{28}$ have estimated that indirect costs incurred by employers because of migraine is $\$ 13$ billion annually, with $\$ 8$ billion due to migraine-related missed workdays. Almost $85 \%$ indicated a reduced capacity to perform housework or chores. ${ }^{29}$

With regard to leisure activities and family relationships, studies have reported that over $40 \%$ of migraineurs reported missing family or social activities as a result of their headaches, ${ }^{30}$ while $32 \%$ avoided making plans for these same types of activities. $^{29}$ Lipton and colleagues ${ }^{29}$ reported that both migraineurs and their household partners indicated that migraine had a negative impact on communication and increased the number of arguments. Forty-three percent of migraineurs in their study felt that they would be better parents without their headaches. As demonstrated by these studies, headache has a profound debilitating impact on both work and family life.

In our patient population, the great majority of patients referred to the headache specialists were in their potentially most productive years of life, between the ages of 20 and 60 . The majority were working outside the home and an additional $11 \%$ were full time home makers. Only $16 \%$ were either unemployed, retired, or on social assistance. The highest educational levels attained by the headache patients in our sample were similar to the general Canadian population. Based on 2001 statistics, $45 \%$ of Canadians attained an elementary or secondary education only compared to $46 \%$ of patients in our sample. Twenty seven percent of our sample had completed some university compared to $26 \%$ of Canadians. ${ }^{31}$ Over half of our sample population was married or living common law. Coupled with our data on the degree of disability suffered by these individuals, our data paints a picture of a population severely affected by their headache disorders, and struggling to remain productive in society. Additionally, given the previous literature regarding the repercussion of headache on family relationships and activities, there is potential for headache to have a major negative impact on immediate family members. In light of the impact headache has on people's lives, the importance of our health care system delivering the best medical care possible for this patient population in order to prevent disability cannot be overemphasized. 
Over $90 \%$ of the patients referred to our headache specialists fell into seven diagnostic categories, with two diagnostic categories, migraine and transformed migraine, accounting for over $70 \%$ of referrals. Although tension-type headaches are more common than migraine in the general population, they made up a much smaller proportion (7.9\%) of the referrals. It is of course likely that a significant proportion of our migraine population may have had tension-type headaches as well, but their migraine was considered the main reason for the referral. The fact that all the headache specialists in our study were neurologists may have influenced the type of patients referred significantly, as migraine is generally considered a neurological condition, whereas patients with headache associated with head injury and with neck problems may have been preferentially referred to other specialists.

As might be expected, the great majority of the patients referred had at least moderate or severe headache attacks, and were still actively suffering from their headache disorder. However, a small minority of patients had not had such headaches in the past month. Although not specifically documented, there are a number of possible reasons for the referral of such patients, including concern about infrequent but problematic migraine auras, and patients with episodic cluster headache who were not in a cluster at the time of referral.

The degree of disability suffered by our patients was very significant. We utilized both the HIT-6 and the MIDAS measurement tools to determine the level of impact and disability our patients experienced because of their headaches. In all diagnostic categories except for "other", fully three-fourths of patients were in the severe impact category on the HIT-6, and over half were in the severe disability category on the MIDAS. Our headache impact results, as measured by the HIT-6, are within the range of results of previous studies on headache patients. Fifty percent $(50 \%)$ of migraine sufferers ${ }^{32}$ and $66 \%$ of episodic headache patients (including migraine) ${ }^{33}$ seen in primary care clinics presented with very severe HIT-6 scores. Among patients in a headache specialty practice, the majority $(87 \%)$ was in the severe impact range. ${ }^{34}$ The MIDAS data, however, indicate that patients captured in our study were more disabled by their headaches compared to patients in other previously published studies, including a population-based study of migraine patients ${ }^{19}$ and headache clinic-based studies of both episodic and chronic migraine..$^{22,24,35,36}$ Based on these comparisons, one explanation for this difference may be that headache patients in Canada may be experiencing delays in referral to headache specialists until a point at which their headache disorders are quite advanced. As well, this indicates that primary care physicians are selective in terms of the patients with headache they refer to specialists.

Our study was completed before publication of the second edition of the International Classification of Headache Disorders of the International Headache Society (IHS) ${ }^{21}$ We therefore used the transformed migraine designation ${ }^{16}$ in our study for patients with migraine and chronic daily headache, as we felt this was the most appropriate classification available for these patients at that time. Broadly speaking, most patients in our study with transformed migraine without medication overuse would meet diagnostic criteria for chronic migraine in the new IHS classification, while patients with transformed migraine with medication overuse would fall into the probable medication overuse headache category.

There are potential limitations involved in our study. Firstly, our study sample was drawn from patients who were seen in headache specialty clinics by neurologists who specialize in headache. Therefore our findings cannot be generalized to the headache population as a whole. Furthermore, not all headache clinics in Canada participated in this study and therefore our results are not population-based and may be subject to referral bias. Given the headache frequency and disability experienced by the patients in our sample, it is likely that our study sample represents the severe end of the headache patient spectrum, comprised of patients who may have posed a treatment challenge to primary care physicians. However, we endeavoured to include specialty headache clinics across Canada and therefore our results are most likely an accurate representation of patients seen by headache neurologists in Canada. It is also likely that our patient population is not very different from patients with headache referred to general neurologists in many parts of Canada, as many areas do not have significant numbers of neurologists sub-specializing in headache.

In conclusion, the patient group referred to headache specialists in Canada is dominated by migraine. It is important that more recognition be given both by physicians and by society at large to the disability produced by migraine disorders. In addition, the high prevalence of symptomatic medication overuse, particularly in the migraine population, needs to be emphasized and addressed by the medical profession. In the overall headache referral population, the high headache frequency found is also noteworthy. Over a third of the patients referred have headache every day. Although most referred patients are in an age range where people are generally in the healthiest and most productive phase of their lives, the patients with headache analyzed in this study were characterized by high degrees of headache related disability. This was the case for all diagnostic categories, and underlies the importance of providing the best possible treatment for this patient group to reduce the impact of headache disorders on the individual, their families, and on society. Future research should also focus on patients with less severe headache problems, particularly patients with migraine, to explore whether progression to a more severe stage can be modified by early effective treatment.

\section{ACKNOWLEDGEMENTS}

The Canadian Headache Outpatient Registry and Database project was funded by a research grant provided by GlaxoSmithKline. The project was carried out under the auspices of the Canadian Headache Society.

\section{REFERENCES}

1. O'Brien B, Goeree R, Streiner D. Prevalence of migraine headache in Canada: a population-based survey. Int $\mathrm{J}$ Epidemiol. 1994;23:1020-6.

2. Schwartz BS, Stewart WF, Simon D, Lipton RB. Epidemiology of tension-type headache. JAMA. 1998;279:381-3.

3. Lambert J, Carides GW, Meloche JP, Gerth WC, Marentette MA. Impact of migraine symptoms on health care use and work loss in Canada in patients randomly assigned in a phase III clinical trial. Can J Clin Pharmacol. 2002;9:158-64. 
4. Edmeads J, Findlay H, Tugwell P, Pryse-Phillips W, Nelson RF, Murray TJ. Impact of migraine and tension-type headache on life-style, consulting behaviour, and medication use: a Canadian population survey. Can J Neurol Sci. 1993;20:131-7.

5. Swarztrauber K, Lawyer BL. Neurologists 2000: AAN Member Demographic and Practice Characteristics. St. Paul, MN: American Academy of Neurology, 2001.

6. Bailey P, Warren S, Buske L. Highlights of the 2002 Canadian Neurological Society (CNS) manpower survey. Can J Neurol Sci. 2005;32:425-32.

7. Hopkins A, Menken M, DeFriese G. A record of patient encounters in neurological practice in the United Kingdom. J Neurol Neurosurg Psychiatry. 1989;52:436-8.

8. Cockerell OC, Goodridge DM, Brodie D, Sander JW, Shorvon SD. Neurological disease in a defined population: the results of a pilot study in two general practices. Neuroepidemiology. 1996;15:7382.

9. Wiles CM, Lindsay M. General practice referrals to a department of neurology. J R Coll Physicians Lond. 1996;30:426-31.

10. Bekkelund SI, Albretsen C. Evaluation of referrals from general practice to a neurological department. Fam Pract. 2002;19:297-9.

11. Salvesen R, Bekkelund SI. Aspects of referral care for headache associated with improvement. Headache. 2003;43:779-83.

12. Hu XH, O'Donnell F, Kunkel RS, Gerard G, Markson LE, Berger ML. Survey of migraineurs referred to headache specialists: care, satisfaction, and outcomes. Neurology. 2000;55:141-3.

13. Bekkelund SI, Salvesen R. Are headache patients who initiate their referral to a neurologist satisfied with the consultation? A population study of 927 patients--the North Norway Headache Study (NNHS). Fam Pract. 2001;18:524-7.

14. Classification and diagnostic criteria for headache disorders, cranial neuralgias and facial pain. Headache Classification Committee of the International Headache Society. Cephalalgia. 1988;8 Suppl 7:S1-96.

15. Siberstein SD, Lipton RB, Solomon S, Mathew NT. Classification of daily and near-daily headaches: proposed revisions to the IHS criteria. Headache. 1994;34:1-7.

16. Silberstein SD, Lipton RB, Sliwinski M. Classification of daily and near-daily headaches: field trial of revised IHS criteria. Neurology. 1996;47:871-5.

17. Kosinski M, Bayliss MS, Bjorner JB, Ware JE Jr, Garber WH, Batenhorst A, et al. A six-item short-form survey for measuring headache impact: the HIT-6. Qual Life Res. 2003;12:963-74.

18. Stewart WF, Lipton RB, Whyte J, et al. An international study to assess reliability of the Migraine Disability Assessment (MIDAS) score. Neurology. 1999;53:988-94.

19. Stewart WF, Lipton RB, Kolodner K, Liberman JN, Sawyer J. Reliability of the migraine disability assessment score in a population-based sample of headache sufferers. Cephalalgia. 1999;19:107-14; discussion 174.

20. Stewart WF, Lipton RB, Kolodner KB, Sawyer J, Lee C, Liberman JN. Validity of the Migraine Disability Assessment (MIDAS) score in comparison to a diary-based measure in a population sample of migraine sufferers. Pain. 2000;88:41-52.
21. The International Classification of Headache Disorders: 2nd edition. Cephalalgia. 2004;24 Suppl 1:S9-160.

22. Cassidy EM, Tomkins E, Hardiman O, O'Keane V. Factors associated with burden of primary headache in a specialty clinic. Headache. 2003;43:638-44.

23. Ferrari A, Pasciullo G, Savino G, Cicero AF, Ottani A, Bertolini A, et al. Headache treatment before and after the consultation of a specialized centre: a pharmacoepidemiology study. Cephalalgia. 2004;24:356-62.

24. Gesztelyi G, Bereczki D. Primary headaches in an outpatient neurology headache clinic in East Hungary. Eur $\mathrm{J}$ Neurol. 2004;11:389-95.

25. Sheftell FD, Feleppa M, Tepper SJ, Volcy M, Rapoport AM, Bigal ME. Patterns of use of triptans and reasons for switching them in a tertiary care migraine population. Headache. 2004;44:661-8.

26. Gerth WC, Carides GW, Dasbach EJ, Visser WH, Santanello NC. The multinational impact of migraine symptoms on healthcare utilisation and work loss. Pharmacoeconomics. 2001;19:197-206.

27. Von Korff M, Stewart WF, Simon DJ, Lipton RB. Migraine and reduced work performance: a population-based diary study. Neurology. 1998;50:1741-5.

28. Hu XH, Markson LE, Lipton RB, Stewart WF, Berger ML. Burden of migraine in the United States: disability and economic costs. Arch Intern Med. 1999;159:813-8.

29. Lipton RB, Bigal ME, Kolodner K, Stewart WF, Liberman JN, Steiner TJ. The family impact of migraine: population-based studies in the USA and UK. Cephalalgia. 2003;23:429-40.

30. Lipton RB, Scher AI, Kolodner K, et al. Migraine in the United States: epidemiology and patterns of health care use. Neurology. 2002;58:885-94.

31. Population 15 years and over by highest level of schooling (19812001 censuses): Statistics Canada, 2001.

32. Veuillaume De Diego E, Lanteri-Minet M. Recognition and management of migraine in primary care: influence of functional impact measured by the headache impact test (HIT). Cephalalgia. 2004;25:184-90.

33. Nachit-Ouinekh F, Dartigues JF, Henry P, Becg JP, Chastan G, Lemaire N, et al. Use of the headache impact test (HIT-6) in general practice: relationship with quality of life and severity. Eur J Neurol. 2005;12:189-93.

34. Kawata AK, Coeytaux RR, Devellis RF, Finkel AG, Mann JD, Kahn K. Psychometric Properties of the HIT-6 Among Patients in a Headache-Specialty Practice. Headache. 2005;45:638-43.

35. Bigal ME, Rapoport AM, Lipton RB, Tepper SJ, Sheftel FD. Assessment of migraine disability using the migraine disability assessment (MIDAS) questionnaire: a comparison of chronic migraine with episodic migraine. Headache. 2003;43:336-42.

36. Bussone G, Usai S, Grazzi L, Rigamonti A, Solari A, D’Amico D. Disability and quality of life in different primary headaches: results from Italian studies. Neurol Sci. 2004;25 Suppl 3:S105-7. 